\title{
Short Report: There is no reason to fear Sars-CoV-2 Omicron but entirely new vaccines are needed to stop all known hCoVs
}

Dr. Carolina Diamandis ${ }^{1}$, Jonathan Feldman ${ }^{1}$, David Seideman ${ }^{1}$, Marianne Kaufmann ${ }^{1}$, and Olga Ivanova ${ }^{1}$

${ }^{1}$ Affiliation not available

January 27, 2022

\section{Hosted file}

Omicron CFR lower than in hCoV infections.pdf available at https://authorea.com/users/410930/ articles/554289-short-report-there-is-no-reason-to-fear-sars-cov-2-omicron-but-entirelynew-vaccines-are-needed-to-stop-all-known-hcovs 